\title{
Students' motivation types in the smart approach to ESP instruction
}

\author{
Ivana Simonova \\ University of Ostrava, Czech Republic
}

Zuzana Prochazkova, Vladimir Lorenc, Jiri Skoda

Jan Evangelista Purkyne University, Czech Republic

\begin{abstract}
This article focuses on the smart approach applied in teaching two topics (referred to as learning contents) within English for Specific Purposes with regard to students' motivation types. It introduces results of the research conducted in this field. The research is based on the definition of the term smart set by Silverio-Fernandez et al. (2018) and the theory of motivation types created by Plaminek (2010), who designed the standardised Motivation Type Inventory distinguishing four motivation types (accurators, coordinators, directors, explorers). Data were collected via didactic tests; quantitative methods were applied to calculate the potential increase in students' knowledge as a difference between pre-test and post-test scores in the didactic tests. In total, 119 prospective teachers from the Faculty of Education and the Faculty of Science at Jan Evangelista Purkyne University participated in this research conducted via quasi-experimental ex-post-facto method for 12 weeks. The smart approach included the exploitation of smart devices and technologies (applications) in faceto-face instruction and in-home preparation for lessons. Three main hypotheses were set to prove whether the smart approach to ESP instruction can be applied to learners of all motivation types. According to the findings, the smart approach suited students of all motivation types; however, coordinators' increase in knowledge was significantly higher compared to explorers and directors in one of the learning contents-
\end{abstract}

Implications for practice of policy:

- All teachers (prospective, novice and in-service) should be trained in conducting smart instruction applying the latest results from psycho- and neuro-didactics.

- Stronger focus should be paid on developing autonomous learning within the learning competence with learners of all ages so that the strengths of smart instruction can be exploited efficiently.

- Currently, all teachers are to acquire distance (online) smart instruction.

Keywords: smart instruction, English for Specific Purposes (ESP), coordinator, explorer, accurator, director, Motivation Type Inventory (MTI)

\section{Introduction}

Information and communication technologies, particularly mobile and smart devices and applications, have become a firm part of the process of instruction at all levels of education. They are reckoned as a strong motivator by numerous authors (e.g., Cirus et al., 2019; Ojeda-Guerra, 2015; Skoda et al., 2015) supporting both intrinsic and extrinsic motivation (Plaminek, 2010). In English for Specific Purposes (ESP), the smart approach, which includes the exploitation of smart devices and technologies (particularly applications), has been considered standard for a decade at minimum (Simonova et al., 2021). Currently, it is unacceptable to design the process of instruction and teach and learn without smart support. As in decades ago, when the use of personal computers and notebooks was the focus of research, attention is now on smart devices. And, when speaking about smart instruction, the question is whether all learners are able to acquire the learning content successfully in this manner. From the point of view of motivation, do smart devices and applications enhance the process of instruction, particularly in ESP? Reflecting the above-mentioned issues, we researched the smart approach to ESP instruction from the view of students' motivation types. The main objective was to analyse students' test scores in single motivation types and thus discover whether the smart approach suits all types of learners. 


\section{Theoretical background}

Currently, the term smart is rather frequently used; however, insufficient effort has been devoted to its precise definition. Having considered numerous sources, in this article and research, we applied the definition by Silverio-Fernández et al. (2018).

\section{Definition of smart}

Silverio-Fernández et al. (2018) aimed at exploring the key features directly or indirectly relating to smart devices across the literature, particularly journals listed in Google Scholar and Science Direct databases within the 2012-2017 period. They used the expression "smart device" as the keyword for search in article titles and abstracts. They then selected 20 articles $(N)$ and undertook a systematic content analysis that revealed distinct features relating to the term "smart" in the analysed articles. These features were grouped under following terms: autonomy, connectivity, context-awareness, user-interaction, mobility and data storage. The terms occurred as follows: connectivity $(N=11 ; 55 \%)$, user-interaction $(N=9 ; 45 \%)$, autonomy $(N=8 ; 40 \%)$, context-awareness $(N=5 ; 25 \%)$, mobility and data storage $(N=4 ; 20 \%$ each).

Based on the analysed articles, autonomy mostly relates to the performance of tasks (Zhang et al., 2013). The use of smart devices as "smart" metres or advanced metres is connected to measuring information through sensors and sending it through a network autonomously (Schleich et al., 2017).

Connectivity refers to establishing a connection to a network. And, as Harwood et al. (2014) stated, this is direct evidence for the utilisation of smart devices for Internet access. Cheng and Mitomo (2017) also referred to connectivity; they emphasised that it is wireless communication capability that makes the devices smart.

Context-awareness is defined as the ability to gather information from the environment through sensors (e.g., camera, microphone, global positioning system) and use it for making autonomous decisions (Godwin et al., 2014).

User-interaction was mentioned in the analysed articles, stating that smart devices are designed to interact with users, that is, persons (Harwood et al., 2014). Contrary to this, Stojkoska and Trivodaliev (2017) opined that smart devices are part of the Internet of Things. As such, the interaction between devices (i.e., things), not between the device (thing) and person, should be considered (Miller, 2015). As a result, Silverio-Fernandez et al. (2018) did not consider user-interaction to be a key feature for being smart.

Data storage represents another important capability. However, it is embedded in the above-mentioned functionalities (autonomy, connectivity, context-awareness). Therefore, it is not considered a key feature of the term smart (Miller, 2015). Mobility (portability) is not classified as a key feature of smartness. Although it is frequently mentioned as a feature of smartphones, tablets and smart watches, it does not apply to every smart device, for example, a smart board, which can be used as a typical whiteboard as well as for work with applications and web pages and also provides drawing tools, text and image visualisation, audio and videorecording (Malkawi, 2017). Smart devices that interact with users can be described by the term smart wearable or hand-held devices (Silverio-Fernández et al., 2018).

Considering the main features of smart devices, we agree with the following definition: A smart device is a context-aware electronic device capable of performing autonomous computing and connecting to other devices by wire or wirelessly for data exchange (Silverio-Fernández et al., 2018).

\section{Motivation theories}

Needs, desires, wants and/or drivers that support the inner processes of individuals and the reasons for their acting or behaving in a particular way and stimulating people to accomplish goals and succeeding in their activities are called motives; and individuals differ in their motives (Simonova, Prochazkova, et al., 2020). A set of motives, motivation, is reflected in several theories. However, the main theoretical concepts focus on different matters. As summarised by Skoda et al. (2015, p. 793), in the theory of motivation, Maslow (1958) arranged human needs in five levels (hierarchy, starting from the physiological of needs, safety, 
love and belonging to esteem and self-actualisation. Once a lower-level need is satisfied, an individual is driven to achieve a higher level. In education, it means a learner is enriched by completing tasks and activities (i.e., learning); these in turn motivate them towards further development.

Compared to this, Herzberg's (1966, cited in Miner, 2005) motivation-hygiene theory works with two factors - motivators, which encourage individuals to work harder, and hygiene factors, which are essential for motivation in the workplace. If these factors are not present, an individual is not motivated. Motivators (satisfiers) comprise recognition, sense of achievement, growth and promotional opportunities, responsibility, meaningfulness of the work. Motivators, both in the work and school environments, build satisfaction, whereas an unfair approach, negative relationships and climate, lack of management and control frustrate individuals and result in no satisfaction. Hygiene factors (dissatisfiers) include salary structure and benefits, company policy, physical working conditions, employees' status, interpersonal relations and job security. If hygiene factors are lacking, dissatisfaction ensues. In the case of no dissatisfaction, the hygiene factors are saturated (Miner, 2005, pp. 61-74 ).

Vroom's expectancy theory (the valence-instrumentality-expectancy model) suggests that an individual is willing to make an effort if they are sure it will enable them to reach their target. The effort includes expectancy - the belief that the activity will result in a successful outcome, instrumentality - the belief that success will bring a reward and valence - the desirability of the reward (Miner, 2005, pp. 94-113). The model, originally designed for the workplace, can be also applied in education, where efforts are expressed through performance towards reaching positive outcomes and rewards Skoda et al. (2015, p. 793). Thus, we can summarise that human motivation to doing anything is determined by the importance an individual assigns to the output of efforts multiplied by the trust that it really leads to success (Gagné \& Deci, 2005). The strength of motivation can be considered from various viewpoints. In the research described below, we applied Plaminek's (2010) theory. There are at least three important reasons why we used this theory:

(1) Plaminek is a Czech scientist, and he developed the theory within the Czech educational environment.

(2) Despite the fact that the theory does not primarily target smart education, it is the most recent of all those mentioned above.

(3) Two of us (Simonova \& Skoda) had experience in applying Plaminek's theory within inquirybased science education of 15-year-old learners (Skoda et al., 2015). The theory has also been used in other research studies (e.g., Bencsik et al., 2016). Despite the fact that authors of this study are from the Slovak Republic, the Czech Republic and Slovak Republic used to be one country and their educational environments are similar. We compare and discussed our findings with the results of both studies - that of Bencsik et al. and that of Skoda et al.

\section{Research methodology}

The Research methodology section is structured in five subsections: (a) the research problem, question and objective are briefly mentioned; (b) three main research hypotheses and related partial ones are stated; (c) research methods and tools are described, with particular information about the inventory detecting students' motivation type and didactic tests; (d) the process of smart instruction is introduced in detail; and, finally, (e) the research sample is described.

\section{Research problem, question and objective}

In this research, we focused on the problem of applying the smart approach applied in teaching and learning the ESP course at higher education level. The ESP course consisted of two topics, referred to as learning contents (LC):

- LC1: Academic English (AE), from the branch of English for Academic Purposes

- LC2: English for Teaching (ET), from the branch of English for Occupational Purposes, as structured in the English language teaching tree by Hutchinson and Waters (1987, p. 17).

The main reason why we focused on these learning contents for research is that they closely relate to the structure of the research sample - prospective teachers, as described below. 
The research question examined whether the smart approach suits learners of different motivation types. The main objective of the research was to discover whether the smart approach as defined below builds appropriate knowledge with students of all motivation types in both learning contents and thus can be exploited in ESP instruction at higher education level.

\section{Research hypotheses}

Three main hypotheses, followed by partial ones, were set to reach the research objective. Considering the fact that the multiple comparison of researched factors is expected in the process of hypotheses verification, hypotheses were set in the null form.

First, in hypothesis H01, the differences between the pre-test and post-test scores were calculated for two learning contents with students of a particular motivation type. This difference is referred to as increase in knowledge further on. If significant differences are detected in partial hypotheses H01.1-H01.8, it means the smart approach is considered contributive and thus can be used in teaching and learning ESP within higher education.

Second, in hypothesis H2, increases in knowledge between the pre-test and post-test scores were compared with regard to particular motivation types. If significant differences are discovered in hypotheses H02.1H02.4, it means students of a particular motivation type appreciate the smart approach to teaching and learning ESP within higher education and it reflects their preferences, as described by Plaminek (2010).

Third, in hypothesis H03, increases in knowledge between pre-test and post-test scores were compared with regard to two learning contents. If significant differences are discovered in hypothesis H03.1 and hypothesis H03.2, it means that students of a particular motivation type are able to acquire learning content better compared with the other types, as described by Plaminek (2010).

To sum up, hypothesis H01 deals with the difference between pre-test and post-test scores to discover whether knowledge increased significantly after the smart instruction. Hypothesis H02 provides a deeper insight into the increase in knowledge from the view of particular motivation types. Hypothesis $\mathrm{H} 03$ searches for differences in the increase in knowledge from the view of the two learning contents. Hypotheses were set as follows:

H01: When applying the smart approach to ESP instruction, there do not exist significant differences in pre-test and post-test scores with students of different motivation types and in different learning contents.

H01.1: When applying the smart approach to ESP instruction, there does not exist statistically significant difference between pre-test and post-test scores with accurators in LC1.

H01.2: When applying the smart approach to ESP instruction, there does not exist statistically significant difference between pre-test and post-test scores with coordinators in LC1.

H01.3: When applying the smart approach to ESP instruction, there does not exist statistically significant difference between pre-test and post-test scores with directors in LC1.

H01.4: When applying the smart approach to ESP instruction, there does not exist statistically significant difference between pre-test and post-test scores with explorers in LC1.

H01.5: When applying the smart approach to ESP instruction, there does not exist statistically significant difference between pre-test and post-test scores with accurators in LC2.

H01.6: When applying the smart approach to ESP instruction, there does not exist statistically significant difference between pre-test and post-test scores with coordinators in LC2.

H01.7: When applying the smart approach to ESP instruction, there does not exist statistically significant difference between pre-test and post-test scores with directors in LC2.

H01.8: When applying the smart approach to ESP instruction, there does not exist statistically significant difference between pre-test and post-test scores with explorers in LC2.

H02: When applying the smart approach to ESP instruction, there do not exist significant differences in increase in knowledge between particular motivation types in different learning contents.

H02.1: When applying the smart approach to ESP instruction, there do not exist significant differences in increase in knowledge with accurators in LC1 compared to LC2.

H02.2: When applying the smart approach to ESP instruction, there do not exist significant differences in increase in knowledge with coordinators in LC1 compared to LC2. 
H02.3: When applying the smart approach to ESP instruction, there do not exist significant differences in increase in knowledge with directors in LC1 compared to LC2.

H02.4: When applying the smart approach to ESP instruction, there do not exist significant differences in increase in knowledge with explorers in LC1 compared to LC2.

H03: When applying the smart approach to ESP instruction, there do not exist significant differences in increase in knowledge in different learning contents between particular motivation types.

H03.1: When applying the smart approach to ESP instruction, there do not exist significant differences in increases in knowledge in LC1 between particular motivation types.

H03.2: When applying the smart approach to ESP instruction, there do not exist significant differences in increases in knowledge in LC2 between particular motivation types.

\section{Research methods and tools}

In foreign language teaching and learning, particularly English, the latest (i.e., smart) devices and technologies have been widely exploited for years (Simonova et al., 2021). This has resulted in the implementation of the smart approach into instruction. Reflecting on the features of smartness analysed above, the smart approach impacts the selection of didactic means and fundamentally changes the entire process of instruction. It allows teaching and learning in a new way which is inconceivable without the smart means and provides a completely new strategy that would not be possible without technology, as defined by the SAMR model designed by Puentedura (n.d.). Technology is not the target but the means for enhancing the process of instruction, often tailored to the students' learning preferences - to motivation types in this case. Therefore, it was not acceptable for us to use the method of pedagogical experiment, when the smart approach is applied in the experimental group only and the control group is taught in another way, without using smart technologies and devices. In the Czech Republic, as a minimum the blended approach is required by the syllabi of all courses at higher education level (National Accreditation Office for Higher Education, 2017). Thus, we used a comparative study exploiting the quasi-experiment and expost-facto method to discover the potential increase in knowledge in acquiring two learning contents with students of different motivation types in the ESP course.

For data collection, two tools were used. First, the Motivation Type Inventory (MTI; Plaminek, 2010) was applied to detect students' motivation types. Second, didactic tests were administered to monitor students' entrance knowledge (pre-test) and final knowledge (post-test). The collected data were processed by appropriate statistic methods ( $t$ test, analysis of variance via ANOVA, post hoc analysis via Fisher's least significant difference test). Analysing the test scores, the increase in knowledge was calculated and considered for particular motivation types and learning contents.

MTI

This tool was applied for detecting students' motivation type. It is structured into two parts. Part 1 focuses on the purpose and means of motivation, when considering respondents on the effectiveness-usefulness scale. Part 2 deals with challenges and safety, when using the stability-dynamics scale. A total of 28 statements are included in MTI, 14 in each part. Respondents express their preferences on a 5-point scale, where they evaluate pairs of motivators in each statement using combinations of points 5:0, 4:1, 3:2, 2:3, $1: 4,0: 5$. Then, the total score is calculated, and the motivation type of each respondent is defined by the combination of scores in both parts of the inventory, that is, by the effectiveness-usefulness and stabilitydynamics scales. Both scales arise from vitality theory, which belongs to the self-determination theory (Deci \& Ryan, 2008). Characteristics of particular motivation types are defined as follows:

- Accurators (stability, usefulness). Reliability is the main feature of accurators. They always try to meet the requirements and fulfil tasks precisely. They are hard both to themselves and others. Their precise performance is based on good work organisation, where the tasks and procedures are clearly defined, and they have enough time to work. They are analytical in their thinking and are able to reach targets. They seem to be calm, keeping their emotions and feelings hidden; they express themselves in explosive situations only. Loyalty to school and respect for teachers are reflected in their decisions, which are made in accordance with regulations and rules. Once they trust a person, they behave openly (Simonova, Prochazkova, et al., 2020, p. 796).

- Coordinators (stability, effectiveness). They like their work and living environment to be pleasant, warm and understanding towards others. Therefore, social relations are important for coordinators. 
These are expressed in their focus on people, their feelings and satisfaction, when talking to others and listening to them. Their empathy is highly developed. Having a strong social intelligence, they are ready to help anyone. However, they are disappointed if others do not help them when they are in need. They are afraid that if they do not fulfil a task successfully, others (e.g., teachers) will be disappointed and angry with them (Simonova, Prochazkova, et al., 2020, p. 796).

- Directors (dynamics, effectiveness). The basic characteristics of directors enable them to follow two lines. First, they succeed in building human relations and social processes. They also like to have an impact on other people and be in the centre of attention. There, they present their ideas and are capable of persuading others. Thus, they often become leaders of social groups (e.g., classmates). Second, they make efforts to achieve the maximum freedom for themselves. They do not like to be under strong criticisms and admit own faults. However, they are good at defending their ideas and opinions and they also appreciate fighting against a strong opponent (Simonova, Prochazkova, et al., 2020, p. 795-796).

- Explorers (dynamics, usefulness). A considerable portion of self-reliance and independence is expressed in their behaviour. They cannot stand to be directed. They appreciate freedom and autonomy, and if a constraint appears, it is a challenge for them to beat it. They are eager for information but impatient. For them, disagreement does not mean to take control over others but to protect their own freedom. In arguments, they focus on the matter at hand; they do not take social relations into consideration. They succeed in disciplines in which maximum rational intelligence, scientific and creative work, not social skills, are required. They are here to solve problems and challenges, mostly in the world of things and results, outside interhuman relations. They are creative, introducing new ideas, searching for new connections and discovering new findings (Simonova, Prochazkova, et al., 2020, p. 795).

\section{Didactic tests}

Two didactic tests were conducted to measure students' increase in knowledge after the smart approach to teaching and learning was applied. The first test (pre-test) detecting students' knowledge before the process of instruction started, was exploited at the beginning of the semester; the second one (post-test) measuring the final knowledge, was used at the end of the semester. The structure of both the didactic tests was identical; however, the tasks differed. Each didactic test consisted of 70 tasks which proportionally covered the course content. All tasks were in the open-answer format. Both the pre-test and post-test were piloted in the same course a year ago, and several slight changes were made in tasks settings.

\section{Process of ESP smart instruction}

The process of instruction was one semester long (from the end of September 2019 to the 1st week of January 2020); it consisted of 12 weeks of instruction, as well as the starting and final weeks for testing.

The smart approach to instruction reflects the key features of this phenomenon as defined above autonomy, connectivity and context-awareness, as well as those of modification and redefinition levels of the substitution augmentation modification redefinition (SAMR) model (Puentedura, 2012). Both levels assist teachers and learners in the implementation of the latest devices and services into teaching and learning and allow teachers to accomplish substantial changes in designing the process of instruction through the use of smart technology. In foreign language instruction, the most frequently used methods are the search for and sharing of learning contents, work in teams (cooperation, collaboration), content visualisation, discussions, exploitation of interactive features in applications and many other activities which would not be enabled without smart technologies. In this research, smart approach is understood as the exploitation of smart devices, technologies and applications both in the face-to-face school and distance after-school learning activities, for example, in searching for and sharing e-sources, particularly parts of massive open online courses, TED Talks and various other web pages dealing with professional topics, in creating networks to share information, discuss, or make comments, explain mistakes. Students attended one 90-minute face-to-face lesson per week; the preparation for the next lesson required another 90-minute period of homework. Face-to-face lessons were mostly devoted to direct conversation - teacher-student, student(s)-student(s) - and providing feedback on homework and students' questions and problems in learning. This approach met the requirements on individualised teaching in groups (mostly of 15 students, 20 as maximum), when the exploitation of smart technologies and applications available on smart devices satisfied each student's needs towards acquiring the required learning content successfully. 
Identical didactic means, that is, teaching methods and aids, were used in teaching both AE and ET topics. Students were to acquire new vocabulary and grammar in AE and ET, listened to professional texts, watched videorecordings, conducted warm-up activities and follow-up discussions, were trained in speaking, finding and presenting facts and arguments to explain and support their opinions, conducting interviews (with potential employers in AE, with learners and parents in ET), writing documents (e.g., curriculum vitae, replies to letters in AE, motivation letters, lesson plans in ET). All activities were conducted both in the face-to-face and distance forms and were enhanced by smart devices, technologies and applications. To sum up, all four skills (reading, writing, speaking, listening) were developed in both learning contents, as well as professional vocabulary and related grammar structures and styles. The professional vocabulary was the only difference in the contents. At the time of the research, all students were prospective teachers enrolled in their third semester. Consequently, they had had some experience in the academic environment, but they had only just started studying subjects dealing with their future teacher profession. Therefore, they found vocabulary and its use in speaking in ET rather difficult as they had not yet acquired all the professional terminology. In contrast, they found the AE vocabulary easier.

\section{Research sample}

The research sample consisted of 121 prospective teachers. Two of them did not fill in the MTI questionnaire correctly; thus, the final number was $N=119$, having the following structure according to Plaminek's MTI: 43 explorers, 33 directors, 23 coordinators and 20 accurators.

They all were students in the Faculty of Education and the Faculty of Natural Sciences at Jan Evangelista Purkyne University. The sample was defined by four characteristics (gender, age, degree, faculty and study program) as follows.

Gender

The sample consisted of 111 females (93\%) and 8 males (7\%).

Age

All participants were aged 19-23.

Degree

Of the participants, 79 of them (66\%) were studying a bachelor's degree (Faculty of Education: $75 \%$; Faculty of Natural Sciences: 25\%) or a master's degree (Faculty of Education: 100\%).

Faculty and study programme

Of the participants, $82 \%$ of them (comprising $1 \%$ males and $99 \%$ females) were enrolled in the Faculty of Education and $18 \%$ of them (comprising $76 \%$ males and $24 \%$ females) in the Faculty of Natural Science.

Participants in the Faculty of Education were enrolled in the following programmes:

- Teaching at Pre-Primary Schools - 39\%

- Teaching at Primary Schools - 26\%

- Teaching at Primary and Special Educational Needs Schools - 13\%

- Czech Language for Media And Communication - 22\%.

Participants in the Faculty of Natural Sciences were enrolled in the following programmes:

- Teaching at Lower Secondary Schools: Information Technologies $-46 \%$

- Toxicology - $18 \%$

- Teaching at Lower Secondary Schools: Biology - $12 \%$

- Chemistry and Biochemistry - $12 \%$

- Teaching at Lower Secondary Schools: Geography and History - 12\%. 


\section{Results}

Research results are presented in three steps, following the three main hypotheses and 14 partial hypotheses. $\mathrm{H} 01$ deals with the difference between pre-test and post-test scores, that is, increase in knowledge. Hypothesis $\mathrm{H} 02$ focuses on differences in increase in knowledge with regards to particular motivation types (accurators, coordinators, directors, explorers). Hypothesis H03 investigates differences in increase in knowledge from the point of view of the two learning contents (LC1, LC2). All statistics were conducted at $\alpha=0.05$ significance level. The data, collected via the MTI and didactic tests (pre-test, post-test), were processed by $t$ test comparison of mean scores, ANOVA and post hoc analysis via Fisher's least significant difference test if significant differences were detected.

\section{Hypothesis H01: Results of testing}

In Step 1, $t$ test for comparison of means in the pre-test and post-test scores was conducted in LC1 for accurators (H01.1), coordinators (H01.2), directors (H01.3) and explorers (H01.4) to discover expected increase in students' knowledge. Then, an identical process was conducted for LC2 (H01.5-H01.8). Results are presented separately for each learning content: for LC1 (see Tables $1 \&$ 2; Figures 1 \& 2) and for LC2 (see Tables $3 \& 4$; Figures $3 \& 4$ ). Null hypotheses were rejected for both LC1 and LC2 and all motivation types. This result suggests that increase in knowledge was statistically significant in all hypotheses (H01.1H01.8) and allows the application of the smart approach in ESP at higher education level.

Table 1

Comparison of means in pre-test and post-test scores in LC1: accurators, coordinators, directors, explorers

\begin{tabular}{lcccccc}
\hline Motivation type & $F$ test & Mean $($ pre $)$ & Mean $($ post) & $t$ test & $P$ value & Decision \\
\hline Accurators & equal variances & 10.90 & 23.20 & -6.406 & $1.58225 \mathrm{E}-7$ & $\mathrm{R}$ \\
Coordinators & equal variances & 9.84 & 24.56 & -7.843 & $3.80598 \mathrm{E}-10$ & $\mathrm{R}$ \\
Directors & equal variances & 11.78 & 23.28 & -6.840 & $4.06167 \mathrm{E}-9$ & $\mathrm{R}$ \\
Explorers & equal variances & 10.38 & 22.90 & -8.467 & 0 & $\mathrm{R}$ \\
\hline
\end{tabular}

Note. R: Reject the null hypothesis for alpha $=.05$

Table 2

ANOVA comparison of pre-test and post-test scores in LC1

\begin{tabular}{llccccc}
\hline Didactic test & Source & Sum of squares & Df & Mean square & $F$ ratio & $P$ value \\
\hline Pre-test & Between groups & 60.8614 & 3 & 20.2871 & .50 & .6810 \\
& Within groups & 4638.53 & 115 & 40.3351 & - & - \\
\multirow{5}{*}{ Post-test } & Total (Corr.) & 4699.39 & 118 & - & - & - \\
& Between groups & 45.1909 & 3 & 15.0636 & .32 & .8123 \\
& Within groups & 5447.45 & 115 & 47.3691 & - & - \\
& Total (Corr.) & 5492.64 & 118 & - & - & - \\
\hline
\end{tabular}

Note. Df: degree of freedom
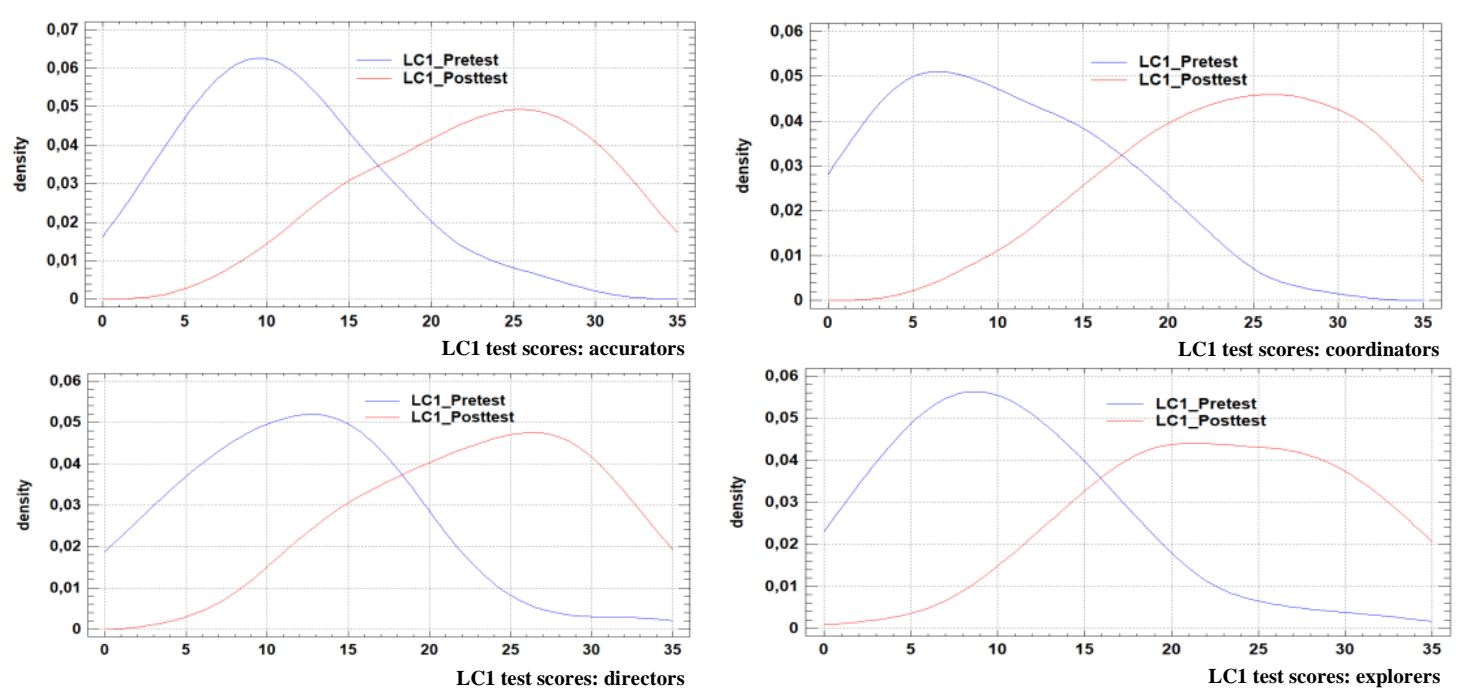
Figure 1. Pre-test and post-test scores in LC1: accurators (top left), coordinators (top right), directors (bottom left), explorers (bottom right)
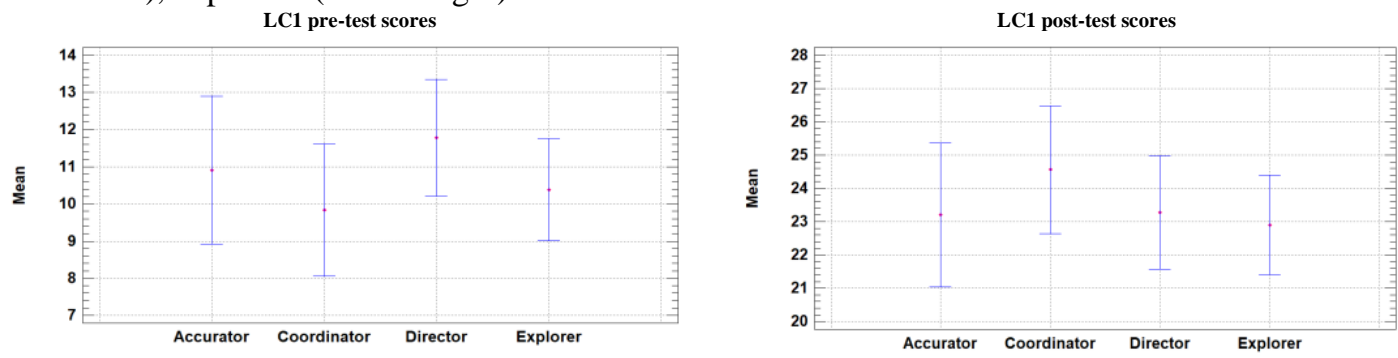

Figure 2. Comparison of pre-test scores (left) and post-test scores (right) in LC1 with accurators, coordinators, directors, explorers

Table 3

Comparison of pre-test and post-test means for LC2

\begin{tabular}{llccccc}
\hline Motivation type & \multicolumn{1}{c}{$F$ test } & Mean $(\mathrm{pre})$ & Mean $(\mathrm{post})$ & $t$ test & $P$ value & Decision \\
\hline Accurators & equal variances & 9.30 & 23.60 & -6.497 & $1.18845 \mathrm{E}-7$ & $\mathrm{R}$ \\
Coordinators & equal variances & 9.12 & 25.60 & -8.762 & $1.59375 \mathrm{E}-11$ & $\mathrm{R}$ \\
Directors & equal variances & 12.50 & 21.50 & -4.945 & $6.115 \mathrm{E}-6$ & $\mathrm{R}$ \\
Explorers & equal variances & 10.98 & 21.07 & -5.885 & $8.37659 \mathrm{E}-8$ & $\mathrm{R}$ \\
\hline
\end{tabular}

Note. R: Reject the null hypothesis for alpha $=.05$

Table 4

ANOVA comparison of pre-test and post-test scores in LC2

\begin{tabular}{llccccc}
\hline Didactic test & Source & Sum of squares & Df & Mean square & $F$ ratio & $P$ value \\
\hline Pre-test & Between groups & 208.47 & 3 & 69.4898 & 1.41 & .2431 \\
& Within groups & 5661.82 & 115 & 49.2332 & - & - \\
& Total (Corr.) & 5870.29 & 118 & - & - & - \\
Post-test & 208.47 & 3 & 69.4898 & 1.41 & .2431 \\
& Between groups & 5661.82 & 115 & 49.2332 & - & - \\
& Within groups & 5870.29 & 118 & - & - & - \\
\hline
\end{tabular}

Note. Df: degree of freedom
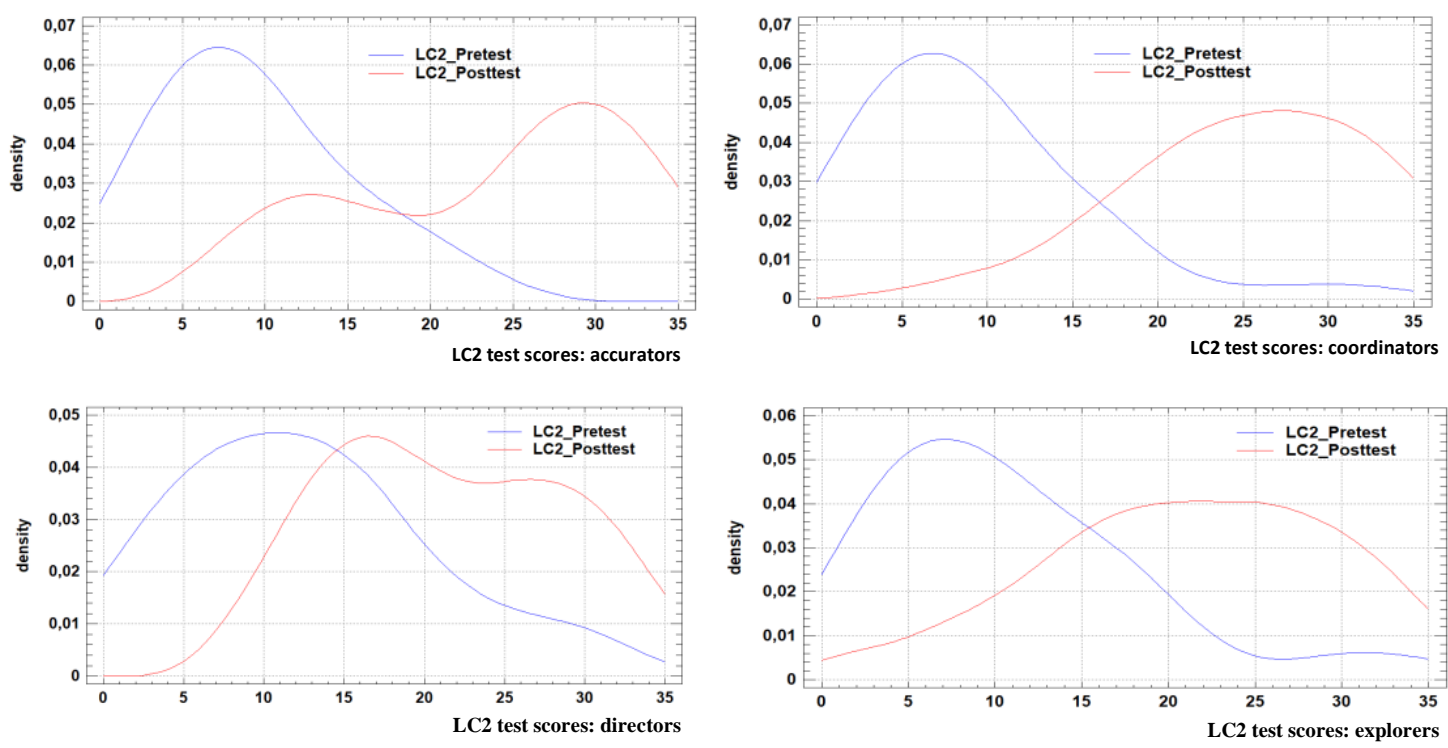

Figure 3. Pre-test and post-test scores in LC2: accurators (top left), coordinators (top right), directors (bottom left), explorers (bottom right) 

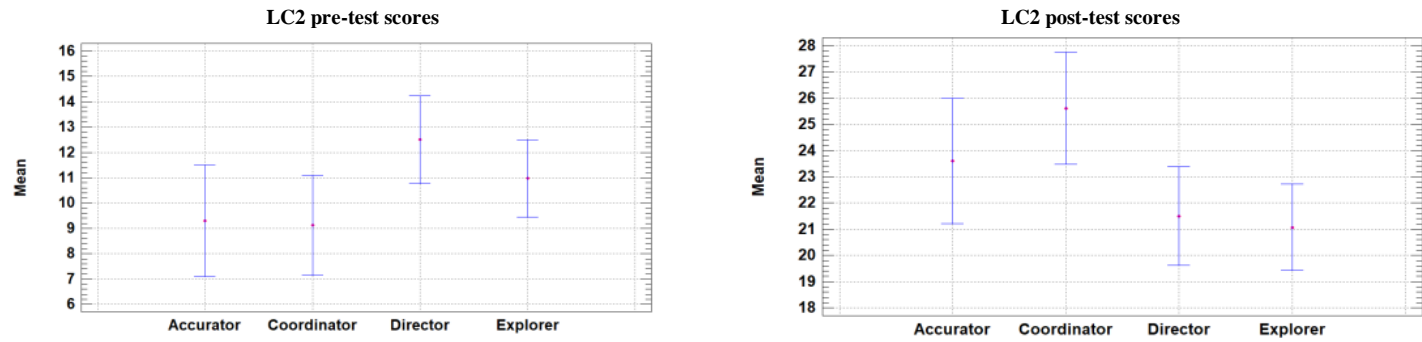

Figure 4. Comparison of pre-test scores (left) and post-test scores (right) in LC2 with accurators, coordinators, directors, explorers

\section{Hypothesis H02: Results of testing}

In Step 2, attention was paid to increases in knowledge from the view of four motivation types, that is, with accurators (H02.1), coordinators (H02.2), directors (H02.3) and explorers (H02.4) in LC1 compared to LC2. First, $t$ test comparison of increases in knowledge was conducted, followed by ANOVA. Null hypotheses were not rejected for any motivation type, that is, differences in increases in knowledge were not significant. Results are presented for each motivation type (see Table 5 \& Figure 5). This result suggests that increases in knowledge in LC1 compared to LC2 for a particular motivation type were not significantly different.

Table 5

Comparison of increases in knowledge with particular motivation types in LC1 compared to LC2

\begin{tabular}{lcccccc}
\hline Motivation type & $F$ test & Mean $($ LC1 1$)$ & Mean $($ LC2) & $t$ test & $P$ value & Decision \\
\hline Accurators & equal variances & 12.30 & 14.30 & -.685 & .497 & DNR \\
Coordinators & equal variances & 14.72 & 16.48 & -.705 & .484 & DNR \\
Directors & equal variances & 11.50 & 9.00 & .953 & .344 & DNR \\
Explorers & equal variances & 12.53 & 10.09 & 1.19 & .235 & DNR \\
\hline
\end{tabular}

Note. DNR: Do not reject the null hypothesis for alpha $=.05$
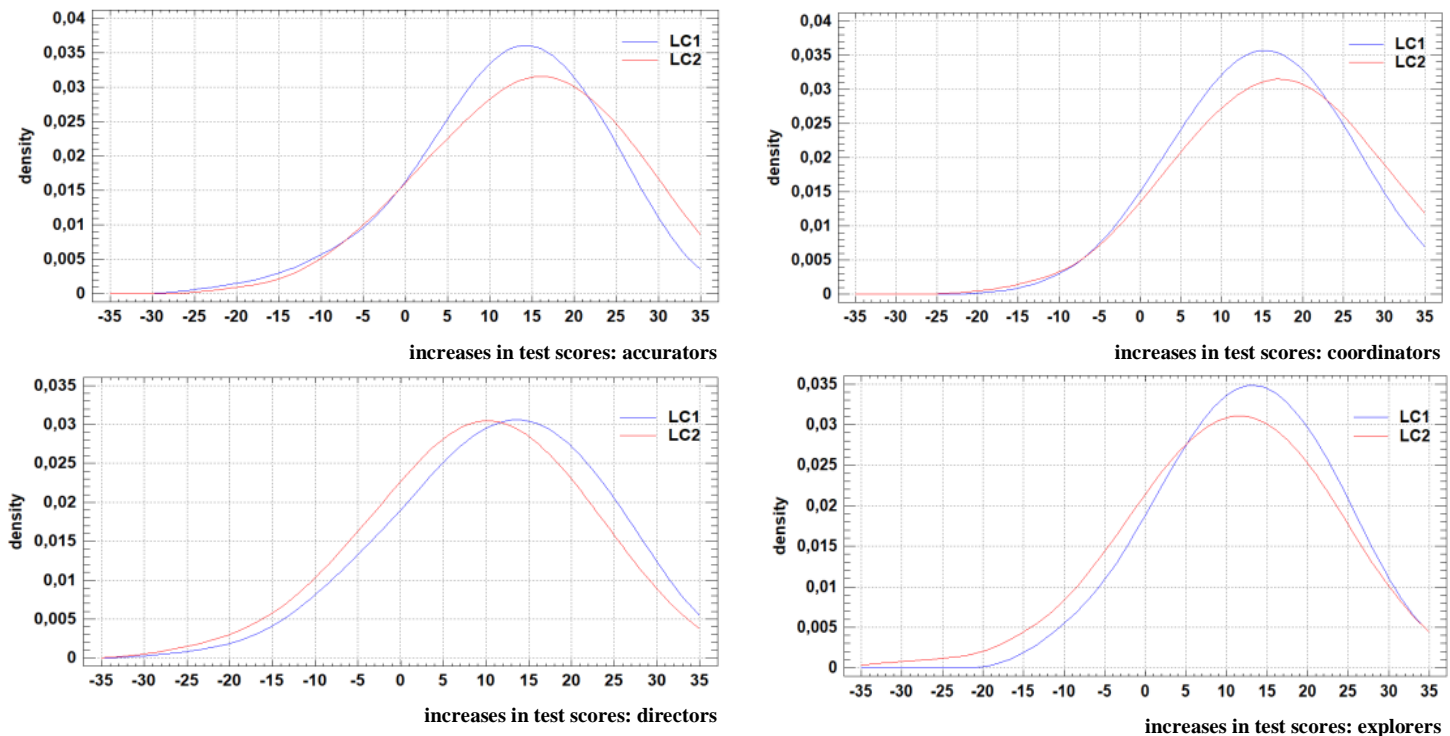

Figure 5. Comparison of increases in knowledge with accurators (top left), coordinators (top right), directors (bottom left), explorers (bottom right) in LC1 compared to LC2

\section{Hypothesis H03: Results of testing}

In Step 3, increases in knowledge between particular motivation types were considered with regard to LC1 (H03.1) and LC2 (H03.2). Data were processed by ANOVA. Hypothesis H03.1 was rejected $(P$ value $=$ 0.5799; see Table 6). However, statistically significant differences were discovered in LC2 $(P$ value $=$ 0.0220; see Table 6). Therefore, Fisher's least significant difference test was applied for LC2. Results 
proved significant differences between coordinators and directors, and coordinators and explorers (see Tables 7 \& 8; Figure 6).

Table 6

ANOVA comparison of increases in knowledge in LC1 compared to LC2

\begin{tabular}{clccccc}
\hline Learning content & \multicolumn{1}{c}{ Source } & Sum of squares & Df & Mean square & $F$ ratio & $P$ value \\
\hline LC1 & Between groups & 152.502 & 3 & 50.8341 & .66 & .5799 \\
& Within groups & 8891.72 & 115 & 77.3193 & - & - \\
\multirow{4}{*}{ LC2 } & Total (Corr.) & 9044.22 & 118 & - & - & - \\
& Between groups & 1045.22 & 3 & 348.406 & 3.33 & .0220 \\
& Within groups & 12028.1 & 115 & 104.592 & - & - \\
& Total (Corr.) & 13073.3 & 118 & & - & - \\
\hline
\end{tabular}

Table 7

Multiple range tests: $95 \%$ LSD

\begin{tabular}{lcc}
\hline Increase in knowledge & Count & Mean \\
\hline Director.LC2_Post-Pre & 32 & 9.0 \\
Explorer.LC2_Post-Pre & 42 & 10.0952 \\
Accurator.LC2_Post-Pre & 20 & 14.3 \\
Coordinator.LC2_Post-Pre & 25 & 16.48 \\
\hline
\end{tabular}

Table 8

Results of Fisher's least significant difference test for LC2

\begin{tabular}{|c|c|c|c|}
\hline Contrast & Sig. & Difference & +/- Limits \\
\hline Accurator.LC2_Post-Pre - Coordinator.LC2_Post-Pre & & -2.18 & 6.07734 \\
\hline Accurator.LC2_Post-Pre - Director.LC2_Post-Pre & & 5.3 & 5.77436 \\
\hline Accurator.LC2_Post-Pre - Explorer.LC2_Post-Pre & & 4.20476 & 5.50362 \\
\hline Coordinator.LC2_Post-Pre - Director.LC2_Post-Pre & * & 7.48 & 5.40735 \\
\hline Coordinator.LC2_Post-Pre - Explorer.LC2_Post-Pre & $*$ & 6.38476 & 5.11723 \\
\hline Director.LC2_Post-Pre - Explorer.LC2_Post-Pre & & -1.09524 & 4.75344 \\
\hline
\end{tabular}

Note. ${ }^{*}$ denotes a statistically significant difference
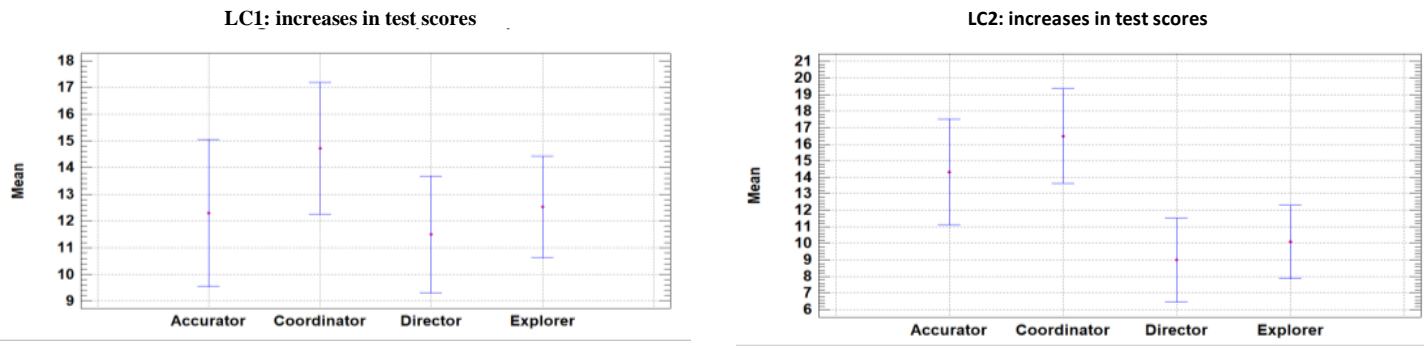

Figure 6. Comparison of increases in knowledge in LC1 (left) compared to LC2 (right)

To sum up, our findings are as follows:

- Null hypotheses H01.1-H01.8 were rejected; that is, significant differences were discovered between pre-test and post-test scores (increases in knowledge) with learners of the four motivation types and LC1 and LC2.

- Null hypotheses H02.1-H02.4 were not rejected; that is, significant differences in increase in knowledge were not discovered from the view of four motivation types.

- Null hypothesis H03.1 was not rejected; that is, significant differences in increase in knowledge were not discovered in LC1.

- Null hypothesis H03.2 was rejected; that is, significant differences in increase in knowledge were discovered in LC2 between coordinators and directors, and coordinators and explorers.

\section{Discussion and conclusions}

Motivation is one of the key issues in the field of education. In this research, however, we focused on students' motivation types (accurators, coordinators, directors, explorers) as described above rather than 
the types of motivation (e.g., extrinsic, intrinsic, introjected, identified). As Czech university students were examined in the research, we applied the MTI by Plaminek, who is a well-recognised scientist in the Czech Republic. The tool has been standardised for Czech language only. For this reason, studies and research conducted by authors outside the Czech Republic are not available. Two of us used the MTI in 2015 in the field of inquiry-based science education with 15-year-old learners in lower secondary schools (Skoda et al., 2015). The research sample consisted of 395 learners; 55 tasks were included in the didactic tests. Results showed significant difference in increase in knowledge (post-test minus pre-test); however, the difference was discovered between directors and accurators, and explorers and accurators, compared to our results finding significant increases between coordinators and directors, and coordinators and accurators in LC2. Bencsik et al. (2016) conducted another study in the field of management among 50 hotel staff members. They proved that employees of different personality types were motivated by different motivation factors and by different tasks. In other words, different motivation tools were needed to motivate different people. This result is comparable to our finding in the educational environment, despite the fact that Bencsik et al. did not go deeper to discover the results of particular types of respondents. Both the results lead us to conclusion 1, stating that learning content (i.e., the field of science education and management versus English for teaching) might be a distinguishing factor (Bencsik et al., 2016; Skoda et al., 2015). In our research, coordinators, preferring and combining the stability and effectiveness, expressed emotional intelligence and expected the others to reflect coordinators' empathy in feedback. This feature is strongly required in the smart approach, where the exploitation of technologies and devices might result in a loss of human contact. As coordinators prefer relationships to results, they make efforts not to fail in meeting others' expectations; they concentrate on building a positive working and learning environment, which, in reality, is the work of teachers. This might be another reason why they reached the highest increase in knowledge in ET, that is, in LC2.

With regard to deep, strategic and surface approaches to learning, which are also reflected in Plaminek's (2010) theory, particularly with accurators and directors, results discovered by Chin and Brown (2000) show that based on discourse analysis, students' actions during the activities and their responses in final interview, there are several apparent differences, mainly in the asking of questions, approach to tasks, nature of explanations and generative thinking and metacognitive activity. If learners apply a deep approach, their answers are more spontaneous; explanations are more sophisticated and refer to personal experience; and they ask questions investigating cause and effect. The findings also suggest that for encouraging a deep learning approach, teachers could provide prompts and contextualised scaffolding, encourage and activate students, predict and explain during activities. Thus, this leads to conclusion 2, stating that this support may result in the development of skills required for autonomous learning within smart instruction, primarily with explorers, and accurators to some extent. Within the smart instruction, how learning contents is acquired is influenced by didactic means. The smart approach as presented in this research can be understood as synonymous to the flipped classroom to some extent. Described by Turan and Goktas (2016) as a type of blended learning strategy, it exploits a reverse approach to teaching and learning, where students are exposed to autonomous acquiring the learning content at home, enhanced by smart devices and technologies and then practising it face-to-face at school. Turan and Goktas also examined the flipped classroom method in comparison to traditional techniques through a quasi-experimental study. The participants, 116 prospective teachers, were monitored for 10 weeks. Results showed that the flipped classroom students reported higher learning achievements and lower cognitive loads than those taught in the traditional way. The instructional efficiency scores of the students in the experimental group were also higher than those in the control group. Turan and Goktas concluded that if designed effectively, the flipped classroom method can be considered a useful approach in higher education. In agreement with them, research conducted under the conditions of the Czech educational system also prove higher efficiency of flipped classroom (e.g., Manenova et al., 2016; Spilka, 2015), as well as those by authors outside the Czech Republic (e.g., Ozudogru \& Aksu, 2020). The COVID-19 pandemic has led to an educational environment for using the flipped smart approach, an approach that is applicable to this situation. Thus, our findings may help those who may not be succeeding in the process of instruction these days, both in teaching and learning. Differences between students with different motivation types and their potential consequent problems in smart learning may discourage them from continuing the studies.

In spite of the fact that smart devices and technologies are all around us, attention should be devoted to their exploitation in the field of education, with a special focus on prospective teachers. In foreign language instruction, the smart approach is rather wide; therefore, further research monitoring this field is strongly required in the future. 
Moreover, we strongly appeal to those responsible for teacher education and training to create conditions for further professional development. Despite the fact that the study results are limited by some characteristics of the research sample, particularly the imbalance in gender $(80 \%$ were female prospective teachers), participating faculties ( $80 \%$ were from the Faculty of Education) and study programmes $(80 \%$ were prospective teachers), they appear promising for the process of smart instruction. The smarter the instruction is, the more that prospective and experienced teachers should be trained - which leads us to conclusion 3: prospective teachers having both the theoretical background and direct experience in smart instruction are those who bring didactic progress to school instruction.

Further research activities are required in the field of smart instruction, either quantitative analyses within the representative sample or deeper qualitative case studies. Reflecting previous works by Czech and world authors on flipped smart learning, further research activities may investigate the instruction of all-age groups of learners, school types and levels, particularly with a special focus on the period of the COVID19 pandemic (Faltynkova et al., 2020; Simonova, Kostolanyova, et al., 2020). Also, smart instruction in other study programmes or courses should be examined. In agreement with the latest studies, support for teachers' motivation is a crucial task in prospective and in-service teacher training (Min et al., 2019; Sanchez-Cortez, 2019).

\section{Acknowledgements}

The research was supported by the Smart City - Smart Region - Smart Community project OP VVV, PO1, N. CZ.02.1.01/0.0/0.0/17_048/0007435.

\section{References}

Bencsik, A., Machova, R., \& Hevesi, E. (2016). The relation between motivation and personality types. International Business Management, 10(3), 183-193. http://docsdrive.com/pdfs/medwelljournals/ibm/2016/183-193.pdf

Cheng, J. W., \& Mitomo, H. (2017). The underlying factors of the perceived usefulness of using smart wearable devices for disaster applications. Telematics and Informatics, 34(2), 528-539. https://doi.org/10.1016/j.tele.2016.09.010

Chin, C., \& Brown, D. E. (2000). Learning in Science: A comparison of deep and surface approaches. Journal of Research in Science Teaching, 37(2), 109-138. https://doi.org/10.1002/(SICI)10982736(200002)37:2\%3C109::AID-TEA3\%3E3.0.CO;2-7

Cirus, L., Manenova, M., \& Skoda, J. (2019). Teachers' attitudes towards ICT and their reflection in the pupils' digital literacy. Educa PF UJEP.

Deci, E. L., \& Ryan, R. M. (2008). Self-determination theory: A macrotheory of human motivation, development, and health. Canadian Psychology, 49(3), 182-185. https://doi.org/10.1037/a0012801

Faltynkova, L., Simonova, I., \& Kostolanyova, K. (2020). Perspectives on distance education in secondary and tertiary education. In C. Busch, M. Steinicke, \& T. Wendler (Eds.), Proceedings of the 19th European Conference on e-Learning (pp. 556-562). Academic Conferences \& Publishing International

Gagné, M., \& Deci, E. L. (2005). Self-determination theory and work motivation. Journal of Organizational Behavior, 26, 331-362. https://doi.org/10.1002/job.322

Godwin, Z. R., Bockhold, J. C., Webster, L., Falwell, S., Bomze, L., \& Tran, N. K. (2013). Development of novel smart device based application for serial wound imaging and management. Burns: Journal of the International Society for Burn Injuries, 39(7), 1395-1402. https://doi.org/10.1016/j.burns.2013.03.021

Harwood, J., Dooley, J. J., Scott, A. J., \& Joiner, R. (2014). Constantly connected: The effects of smart devices on mental health. Computers in Human Behavior, 34, 267-272. https://doi.org/10.1016/j.chb.2014.02.006

Hutchinson, T., \& Waters, A. (1987) English for Specific Purposes: A learning-centered approach. Cambridge University Press. https://doi.org/10.1017/CBO9780511733031

Malkawi, N. (2017). The effect of using smart board on the achievement of tenth grade students in English language and on verbal interaction during teaching in public schools. International Research in Education, 5(1), 197-208. https://doi.org/10.5296/ire.v5i1.11035 
Manenova, M., Tauchmanova, V., \& Burgerova, J. (2016). Flipped classroom from the point of view of teachers of secondary technical schools. In L. Gómez Chova, A. López Martínez, \& I. Candel Torres (Eds.), Proceedings of the 9th annual International Conference of Education, Research and Innovation (pp. 7366-7373). IATED Academy. https://doi.org/10.21125/iceri.2016.0677

Maslow, A. H. (1958). A dynamic theory of human motivation. In C. L. Stacey \& M. DeMartino (Eds.), Understanding human motivation (pp. 26-47). Howard Allen Publishers. https://doi.org/10.1037/11305-004

Miller, M. (2015). The Internet of things: How smart TVs, smart cars, smart homes, and smart cities are changing the world. Pearson Education.

Min, Q. S., Wang, Z. F., Liu, N. (2018). Integrating a cloud learning into English-medium instruction to enhance non-native English-speaking students' learning. Innovations in Education and Teaching International, 56(4), 493-504. https://doi.org/10.1080/14703297.2018.1483838

Miner, J. B. (2005). Organizational behavior: Essential theories of motivation and leadership (1st ed.). Routledge. https://doi.org/10.4324/9781315702018

National Accreditation Office for Higher Education. (2017). Metodické materiály pro př́pravu a hodnocení žádostí o akreditaci studijního programu [Methodological instructions for preparation and evaluation of application for a study programme accreditation]. https://www.nauvs.cz/attachments/article/71/13 metodika_posuzovani_2017 07.pdf

Ojeda-Guerra, C. N. (2015). Using ICT to motivate students in a heterogeneous programming group. In T. Mascio, R. Gennari, P. Vittorini, \& F. De la Prieta (Eds.), Methodologies and intelligent systems for technology enhanced learning: Vol. 374. Advances in intelligent systems and computing (pp. 3340). Springer. https://doi.org/10.1007/978-3-319-19632-9_5

Ozudogru, M., \& Aksu, M. (2020). Pre-service teachers' achievement and perceptions of the classroom environment in flipped learning and traditional instruction classes. Australasian Journal of Educational Technology, 36(4), 27-43. https://doi.org/10.14742/ajet.5115

Plaminek, J. (2010). Tajemstvi motivace - jak zař́dit, aby pro vás lidé rádi pracovali (2nd ed.) [The secret of motivation: How to make people like working for you]. Grada.

Puentedura, R. (2012, August 23). The SAMR model: Background and exemplars. Ruben R. Puentedura's Blog. http://www.hippasus.com/rrpweblog/archives/2012/08/23/SAMR_BackgroundExemplars.pdf

Sanchez-Cortes I., \& Súarez, J. M. (2019). Métodos de enseñanza, compromiso y metas del profesorado en modalidad b-learning [Teaching methods, teacher engagement and goals in b-learning]. Aula Abierta, 48(3), 311-319. https://doi.org/10.17811/rifie.48.3.2019.311-320

Schleich, J., Faure, C., \& Klobasa, M. (2017). Persistence of the effects of providing feedback alongside smart metering devices on household electricity demand. Energy Policy, 107, 225-233. https://doi.org/10.1016/j.enpol.2017.05.002

Silverio-Fernández, M., Renukappa, S., \& Suresh, S. (2018). What is a smart device? A conceptualisation within the paradigm of the IoT. Visualization in Engineering, 6, Article 3. https://doi.org/10.1186/s40327-018-0063-8

Simonova, I., Kostolanyova, K., \& Faltynkova, L. (2020). Smart didactic means in learning English for specific purposes. In C. Busch, M. Steinicke, \& T. Wendler (Eds.), Proceedings of the 19th European Conference on e-Learning (pp. 468-475). Academic Conferences \& Publishing International.

Simonova, I., Prochazkova, Z., \& Lorenc, V. (2021). Smart and/or mobile: An investigation within Czech university students. In J. S. Raj (Ed.), International conference on mobile computing and sustainable informatics (pp. 361-372). Springer. https://doi.org/10.1007/978-3-030-49795-8 35

Simonova I., Prochazkova Z., Lorenc V., \& Skoda J. (2020). Smart approach to ESP instruction. In S. Cheung, R. Li, K. Phusavat, N. Paoprasert, \& L. Kwok (Eds.), Lecture notes in computer science: Vol. 12218. Blended learning: Education in a smart learning environment (pp. 163174). Springer. https://doi.org/10.1007/978-3-030-51968-1_14

Skoda, J., Doulik, P., Bilek, M., \& Simonova, I. (2015). The effectiveness of inquiry-based science education in relation to the learners' motivation types. Journal of Baltic Science Education, 14(6), 791-803. http://www.scientiasocialis.lt/jbse/?q=node/472

Spilka, R. (2015). Learner-content interaction in flipped classroom model. International Journal of Information and Communication Technologies in Education, 4(3), 53-60. https://doi.org/10.1515/ijicte-2015-0014

Stojkoska, B. L. R., \& Trivodaliev, K. V. (2017). A review of internet of things for smart home: Challenges and solutions. Journal of Cleaner Production, 140, 1454-1464.

https://doi.org/10.1016/j.jclepro.2016.10.006 
Turan, Z., \& Goktas, Y. (2016). The flipped classroom: Instructional efficiency and impact of achievement and cognitive load levels. Journal of e-Learning and Knowledge Society, 12(4), 51-62. https://doi.org/10.20368/1971-8829/1122

Zhang, Y., Mao, M., Rau, P. P., Choe, P., Bela, L., \& Wang, F. (2013). Exploring factors influencing multitasking interaction with multiple smart devices. Computers in Human Behavior, 29(6), 25792588. https://doi.org./10.1016/j.chb.2013.06.042

Corresponding author: Ivana Simonova, ivana.simonova@osu.cz

Copyright: Articles published in the Australasian Journal of Educational Technology (AJET) are available under Creative Commons Attribution Non-Commercial No Derivatives Licence (CC BYNC-ND 4.0). Authors retain copyright in their work and grant AJET right of first publication under CC BY-NC-ND 4.0.

Please cite as: Simonova, I., Prochazkova, Z., Lorenc, V., \& Skoda, J. (2021). Students' motivation types in the smart approach to ESP instruction. Australasian Journal of Educational Technology, 37(2), 6680. https://doi.org/10.14742/ajet.6677 